\title{
Birth weight and cognitive performance in older women: the Rancho Bernardo study
}

\author{
Kirsten Erickson • Donna Kritz-Silverstein • \\ Deborah L. Wingard • Elizabeth Barrett-Connor
}

Received: 11 March 2009/Accepted: 7 August 2009/Published online: 27 August 2009

(C) The Author(s) 2009. This article is published with open access at Springerlink.com

\begin{abstract}
Low birth weight is associated with poorer cognitive function from infancy through early adulthood, but little is known about low birth weight and cognitive performance in the elderly. This study examines the association of birth weight with cognitive function in community-dwelling older women. Participants were 292 community-dwelling women aged 55-89 (median= 71 years) who attended a 1988-91 clinic visit when cognitive function was assessed, and responded to a 1991 mailed questionnaire assessing birth weight. All analyses were adjusted for age and education. Birth weight ranged from 2 to 12 pounds (lbs; mean=7.4 \pm 1.9 ). When birth weight was categorized into tertiles (2-6.9 lbs, 7-8 lbs, and 8.1-12.4 lbs), women in the lowest tertile had significantly lower ("poorer") scores on Serial 7's, a test of concentration and calculation $(p<0.05)$. Other birth weight categorizations (lowest quartile or quintile, or birth weight $<5.5 \mathrm{lbs}$ vs. 5.6-8.9 lbs and $\geq 9 \mathrm{lbs}$ ) did not improve the prediction of poor performance on Serial 7's. Birth weight as a continuous variable was significantly and positively associated with Serial 7's test scores $(p=0.04)$. Results suggest that small decrements in cognitive function tasks involving calculation may persist throughout life in women who were of relatively low birth weight. Although this association could be spurious, it deserves further evaluation.
\end{abstract}

Keywords Birth weight $\cdot$ Cognitive function · Memory · Postmenopausal women

K. Erickson • D. Kritz-Silverstein $(\square) \cdot$ D. L. Wingard

E. Barrett-Connor

Department of Family \& Preventive Medicine,

University of California, San Diego,

San Diego, CA, USA

e-mail: dsilverstein@ucsd.edu
Low birth weight (LBW), defined as infants weighing $\leq 2,500 \mathrm{~g}(5 \mathrm{lbs}, 8 \mathrm{oz})$ complicates $8.2 \%$ of live births in the United States (Martin et al. 2006; Hamilton et al. 2006), and contributes substantially to infant and childhood morbidity, particularly with respect to neurological outcomes (Saigal et al. 2000; Taylor et al. 2006; Goldenberg and Culhane 2007; Hack 2006). LBW has been associated with poorer performance on cognitive function tests from infancy through early adulthood (Sorensen et al. 1997).

One study of a British birth cohort investigated the association between birth weight and cognitive function at various ages (Richards et al. 2002), but did not evaluate cognitive function after age 43. To our knowledge, the only previous study of cognitive function in old age as related to birth weight (ascertained by birth records), included 1,576 men and women aged 48-74 years; only two cognitive function tests were administered, (IQ test and vocabulary). Neither was associated with birth weight (Martyn et al. 1996).

This study assesses the association of birth weight with 12 standard cognitive function tests in community-dwelling women aged 55 years and older who also reported their birth weight.

\section{Methods \\ Participants}

In $1972-1974,82 \%$ of the residents of Rancho Bernardo, a middle-class, predominantly Caucasian, southern California community, were enrolled in a study of heart disease risk factors. These individuals were followed ever since with yearly mailed questionnaires and periodic clinic evaluations. Eighty percent of the surviving community-dwelling 
men $(n=811)$ and women $(n=1229)$ attended a 1988-91 follow-up clinic visit, when cognitive function tests were administered. In 1991, surviving members of the cohort were mailed a questionnaire asking about birth weight and their source of information (birth certificate, family Bible, baby book, parent, other). Too few men knew their birth weight for meaningful analysis, and were excluded from consideration. After excluding 25 women aged $<55$ years in 1988-1991, 200 who did not complete all cognitive function tests and 712 unable to provide birth weight information, there remained 292 women aged $\geq 55$ for this analysis. All were ambulatory and gave written, informed consent. This study was approved by the University of California, San Diego Human Research Protections Program.

\section{Procedures}

Self-administered questionnaires were used to assess age, smoking history, and alcohol consumption. Medication use, including estrogen-replacement therapy, was confirmed by examination of prescriptions or pills brought to the clinic for that purpose. Trained personnel individually administered 12 cognitive function tests, all with demonstrated reliability and validity. These tests included:

The Buschke-Fuld Selective Reminding Test (Buschke and Fuld 1974) to assess short- and long-term storage and retrieval of spoken words. Ten unrelated words are read to participants at a rate of one every $2 \mathrm{~s}$ for up to six trials. Immediately after, participants are asked to recall the list. Points are based upon the number of items and trials needed for recall. Measures of long- and short-term memory and total recall are obtained. Higher scores on short-term memory indicate poorer performance.

The Heaton Visual Reproduction Test (Russell 1975; Weschler 1945), assesses memory for geometric forms. Three stimuli of increasing complexity are presented one at a time, for $10 \mathrm{~s}$ each. Participants reproduce the figures immediately (short-term memory), and after $30 \mathrm{~min}$ (longterm memory). Participants are asked to copy the stimulus figures to assess visuospatial impairments.

The Mini-Mental State Examination (MMSE) (Folstein et al. 1975; Tombaugh and McIntyre 1992) assesses orientation, registration, attention, calculation, language and recall. Total MMSE scores range from 0-30. Two MMSE items were analyzed separately; counting backward from 100 by sevens (Serial 7's), which assesses calculation, and spelling the word "world" backwards which assesses attention. Maximum possible score is 5 for each item.

Two items from the Blessed et al. (Blessed et al. 1968) Information-memory-concentration test assess concentration by having participants name the months of the year backward, and assess memory by asking participants to recall a five-part name and address following a 10-min delay. Two points are given for correctly naming the months of the year backward and one point is given for each part of the name and address recalled correctly. The maximum possible score is 7 .

The Trail-making Test, part B (Trails B), from the Halstead-Reitan Neuropsyhological Test Battery (Reitan 1958), tests visuomotor tracking and attention. Participants scan a page to identify numbers and letters in a specified sequence while shifting from number to letter sets. A maximum of $300 \mathrm{~s}$ is given; scoring is the time taken to finish the test. Higher scores indicate poorer test performance.

Category fluency (Borkowski et al. 1967) is assessed by having participants name as many animals as possible in $1 \mathrm{~min}$. The score is the number of animals correctly named. Repetitions, variants, and intrusions are not counted.

A mailed questionnaire in 1991 asked participants to give their birth weight and source of information with response choices of birth certificate, baby book, family bible, parent and unknown.

\section{Statistical analysis}

Descriptive statistics were calculated for all continuous and categorical variables. All analyses were adjusted for age and education. Comparisons of cognitive function scores by birth weight tertile were performed with analysis of covariance. Multiple regression analyses were used to examine the association of birth weight in tertiles and as a continuous variable with each cognitive function score after adjustment for confounders. For these analyses, variables were identified as confounders if their removal from the model yielded a change of $\geq 10 \%$ in the beta weight for birth weight. Analyses were repeated using other definitions of low birth weight $(\leq 5.5 \mathrm{lbs}$ vs. $5.6-8.9 \mathrm{lbs}$ and $\geq 9 \mathrm{lbs}$; quartiles; and quintiles). To test for selection bias, those with and without birth weight data were compared on age, education, cigarette smoking, alcohol use and estrogen use.

SAS, version 8.0 for Windows, (SAS Institute Inc., Cary, $\mathrm{NC}$ ), was used for analysis; all tests were two tailed, $p<$ 0.05 was considered statistically significant. No adjustment was made for multiple comparisons as analyses were exploratory; exact $p$-values are shown instead.

\section{Results}

Age ranged from 55-89 years with an average of 71.1 (median 71.0). Information on birth weight was obtained from birth certificates for $31.5 \%$, family Bibles for $1.0 \%$, and baby books for $10.3 \%$ and parents for $54.1 \%$. Mean birth weight was $7.4 \pm 1.8$ pounds (median=7.5). Only 28 
women weighed $\leq 5.5$ pounds at birth. Table 1 compares characteristics by birth weight tertile. There were significantly fewer past and current smokers among women in the lowest tertile as compared to those in the middle and highest tertiles $(p=0.03)$, but there were no significant differences by birth weight tertile on age, education, alcohol intake, or estrogen therapy use.

Table 2 shows cognitive function by birth weight tertile adjusted for age and education. Women in the lowest birth weight tertile had significantly lower ("poorer") test scores on Serial 7's compared to women in the middle and highest birth weight tertiles $(p<0.05)$. No differences by birth weight tertile were observed on the other eleven cognitive function tests. Only 15 women in this sample had diabetes; 4 were in the lowest birth weight tertile. Adjusting analyses for the presence of diabetes or for current body mass index did not materially alter the results. Using other cutpoints for birth weight categorization (e.g., quartiles, quintiles, or birth weight $\leq 5.5 \mathrm{lbs} / 7-8 . \mathrm{lbs} / \geq 9 \mathrm{lbs})$ yielded similar differences only for Serial 7's (data not shown). Although mean values obtained for Serial 7's were similar, differences were of borderline statistical significance $(p<0.06)$ when birth weight was classified as $\leq 5.5 \mathrm{lbs} / 7-8.9 \mathrm{lbs} /$ $\geq 9 \mathrm{lbs}$, most likely due to low statistical power (.48).

Table 3 shows the results of regression analyses examining the association of birth weight as a continuous variable with cognitive function scores after adjustment for age and education. As shown, birth weight as a continuous variable, was significantly and positively associated with Serial 7's scores $(p=0.04)$, but was not associated with any other cognitive function scores. Adjusting analyses for the presence of diabetes yielded similar results.
Selection bias analysis showed that women who reported birth weight were significantly younger $(p<0.001)$, more educated $(p<0.001)$, and more likely to have ever used estrogen replacement $(p=0.03)$ than those who did not have birth weight information $(n=712)$, but there were no differences in smoking or alcohol use.

\section{Discussion}

From 1960 to 2000, approximately 20,000 infants were born each year weighing $\leq 1,000 \mathrm{~g}$ ( 2.2 pounds). Although the mortality of LBW infants decreased during this time period, the prevalence of significant disabilities has increased substantially (Goldenberg and Culhane 2007). LBW has been associated with poorer performance on cognitive function tests from infancy through early adulthood (Sorensen et al. 1997; Shenkin et al. 2001; Richards et al. 2001; Jefferis et al. 2002; Matte et al. 2001). However, few studies examine whether the effects of LBW persist throughout a person's lifetime and into old age.

This study of older women showed no evidence of residual cognitive impairment on 11 of 12 cognitive function tests for those reporting lower birth weights, but there was evidence for a long-term effect of low birth weight on the only cognitive function test involving calculation. These results are in partial accord with those of Richards et al. (2002) who reported that birth weight was significantly associated with poorer cognitive function scores on reading comprehension, verbal memory and math in participants aged 8-43. Results of our study disagree with those of Martyn et al. (1996) who reported no

Table 1 Sample characteristics of women $(N=292)$ aged 55-89 years by tertile of birth weight; Rancho Bernardo, CA, 1988-1991

\begin{tabular}{|c|c|c|c|c|c|c|}
\hline & All & $\begin{array}{l}\text { Lowest tertile } \mathrm{b}^{\mathrm{b}} \\
2.0-6.9 \mathrm{lbs} \\
(n=90)\end{array}$ & $\begin{array}{l}\text { Middle tertile }{ }^{\mathrm{b}} \\
7.0-8.0 \mathrm{lbs} \\
(n=113)\end{array}$ & $\begin{array}{l}\text { Highest tertile }{ }^{\mathrm{b}} \\
8.1-12.4 \mathrm{lbs} \\
(n=89)\end{array}$ & $F$ or $\chi^{2}$ & $P$-value \\
\hline \multicolumn{7}{|l|}{ Continuous Variable mean (SD) } \\
\hline Age (years) & $71.1(8.6)$ & $71.1(8.2)$ & $71.4(8.8)$ & $70.9(8.9)$ & 0.07 & 0.93 \\
\hline \multicolumn{7}{|l|}{ Categorical Variables (\%) } \\
\hline Some college ${ }^{a}$ & 71.8 & 71.9 & 74.3 & 68.5 & 0.83 & 0.66 \\
\hline Smoking & & & & & 1.30 & 0.03 \\
\hline Never & 49.0 & 19.2 & 17.5 & 12.3 & & \\
\hline Past & 40.4 & 8.6 & 17.1 & 14.7 & & \\
\hline Current & 10.6 & 3.1 & 4.1 & 3.4 & & \\
\hline Alcohol intake ( $\geq 3$ times/week) & 41.1 & 41.1 & 41.6 & 40.4 & 0.03 & 0.99 \\
\hline Ever use estrogen & 77.9 & 71.9 & 80.4 & 80.9 & 2.72 & 0.26 \\
\hline
\end{tabular}

All variables had $<5 \%$ missing

${ }^{\text {a }}$ College defined as $>$ High school versus $\leq$ High school

${ }^{\mathrm{b}}$ Means and medians of birth weights within each tertile were: Tertile $1:$ mean $=5.3 \mathrm{lbs}$, median=5.2 lbs; Tertile 2:mean=7.6 lbs, median=7.5; and Tertile 3: mean $=9.5 \mathrm{lbs}$, median $=9.0 \mathrm{lbs}$ 
Table 2 Age- and education-adjusted comparisons of scores on cognitive function tests by birth weight tertile in women ( $n=292)$; Rancho Bernardo, CA, 1988-1991

\begin{tabular}{lccc}
\hline Cognitive function test mean (SD) & $\begin{array}{l}\text { Lowest tertile } \\
2.0-6.91 \mathrm{bs} \\
(n=90)\end{array}$ & $\begin{array}{l}\text { Middle tertile } \\
7.0-8.01 \mathrm{bs} \\
(n=113)\end{array}$ & $\begin{array}{l}\text { Highest rertile } \\
8.1-12.41 \mathrm{bs} \\
(n=89)\end{array}$ \\
\hline Buschke total recall & $42.0(9.7)$ & $42.3(8.0)$ & $37.5(10.6)$ \\
Buschke LTM & $37.0(12.6)$ & $4.9(3.8)$ & $35.9(12.1)$ \\
Buschke STM & $5.0(3.6)$ & $10.6(3.6)$ & $5.4(3.9)$ \\
Heaton visual copying & $10.2(3.3)$ & $7.8(4.1)$ & $10.3(3.2)$ \\
Heaton visual LTM & $8.0(4.0)$ & $15.6(2.0)$ & $7.3(3.6)$ \\
Heaton visual STM & $15.5(1.9)$ & $27.6(1.4)$ & $15.6(1.6)$ \\
MMSE & $27.7(1.8)$ & $4.2(1.2)^{*}$ & $27.8(1.6)$ \\
Serial 7's & $3.9(1.2)$ & $4.9(0.5)$ & $4.2(1.2)^{*}$ \\
World backward & $4.9(0.5)$ & $6.4(0.9)$ & $4.9(0.4)$ \\
Total blessed & $6.3(1.4)$ & $123.7(56.2)$ & $132.3(1.1)$ \\
Trails B & $122.8(59.8)$ & $18.9(5.1)$ & $18.5(4.6)$ \\
Category fluency & $18.0(4.6)$ & & \\
\hline
\end{tabular}

Results of analysis of covariance

${ }^{a}$ Higher score indicates poorer test performance

${ }^{*} p \leq 0.05$ for comparison with Tertile 1

association between birth weight and intelligence and vocabulary tests in men and women aged 48-74. However, that study, unlike the present study, did not include a test involving calculation. To our knowledge, no other studies address the association of low birth weight and cognitive function in older individuals.

Barker's fetal origins hypothesis contends that undernutrition during developmentally sensitive periods causes an adaptation response by the fetus that may biologically

Table 3 Adjusted associations of birth weight as a continuous variable with cognitive function test scores in women $(n=292)$; Rancho Bernardo, CA, 1988-1991

\begin{tabular}{lrrr}
\hline Cognitive function tests & \multicolumn{1}{l}{$\mathrm{t}$} & $p$-value \\
\hline Buschke total recall & -0.08 & -0.30 & 0.77 \\
Buschke LTM & -0.08 & -0.22 & 0.83 \\
Buschke STM $^{\mathrm{a}}$ & 0.00 & 0.04 & 0.97 \\
Heaton visual copying & 0.05 & 0.48 & 0.63 \\
Heaton visual LTM & -0.00 & 0.01 & 0.99 \\
Heaton visual STM & 0.07 & 1.24 & 0.22 \\
MMSE & 0.03 & 0.56 & 0.57 \\
Serial 7's & 0.08 & 2.09 & $\mathbf{0 . 0 4}$ \\
World backward & -0.00 & -0.14 & 0.89 \\
Trails B & 2.23 & 1.34 & 0.18 \\
Category fluency & 0.08 & 0.54 & 0.59 \\
Total blessed & 0.05 & 1.42 & 0.16 \\
\hline
\end{tabular}

Results of analysis of covariance; models adjusted for age and education. Units of birth weight measured in pounds

${ }^{a}$ Higher score indicates poorer test performance 'program' adult chronic disease (Barker 2004). Low birth weight is presumed to indicate undernutrition of the fetus in utero. Studies in laboratory animals provide evidence for a programming mechanism (McCance and Widdowson 1974; Winick and Noble 1966). Barker's hypothesis has received support in humans from several epidemiologic studies linking low birth weight to coronary heart disease, diabetes, obesity and hypertension in adulthood (Barker 1995; Lithell et al. 1996; Hales et al. 1991; Yarbrough et al. 1998; Leon et al. 1996; Law et al. 1993).

Low birth weight is a risk factor for neurodevelopmental disabilities in early childhood (Lorenz et al. 1998) making it biologically plausible that its effects on cognitive development persist throughout the lifespan. Malnutrition resulting in LBW affects the morphology, physiology, and neurochemistry of the brain during critical periods of central nervous system development, which may have implications for future cognitive function (Morgane et al. 1993). Numerous studies report that very low birth weight children have more academic difficulties than normal birth weight children (Hack et al. 1992; Saigal et al. 1991a). These difficulties are found even when children with obvious mental or neurological impairments are excluded from consideration (Klebanov et al. 1994; Klein et al. 1989). Areas of functioning that most consistently distinguish very low birth weight children from normal controls include math achievement, attention and perceptual motor skills (Szatmari et al. 1993). One longitudinal study showed that teenagers who were extremely low birth weight as newborns, function less well on intellectual measures compared to age-matched peers, especially in arithmetic 
(Saigal et al. 2000). Difficulties in math among children of low birth weight have also been reported by others (Klebanov et al. 1994; Klein et al. 1989; Weiner et al. 1968; Saigal et al. 1991b; Taylor et al. 1995; Rickards et al. 1988; Botting et al. 1998), a finding often independent of IQ (Klebanov et al. 1994; Klein et al. 1989; Botting et al. 1998). Results of this study show that as compared to women with higher birth weight, those with lower birth weight had significantly poorer scores on Serial 7's, a test assessing calculation, and suggest that the early differences persist into old age. The lack of differences on tests in other cognitive dimensions is in accord with studies in children. Furthermore, the difference observed in the present study was independent of age and education, suggesting an underlying deficit that cannot be ameliorated by education or the passage of time.

Potential limitations of this study are acknowledged. A large proportion of these elderly women did not know their birth weight and only $42.8 \%$ had paper documentation. Many were born years before states issued birth certificates, and at a time when many babies were born at home. The small number of women with documented birth weight eliminates the possibility of a sensitivity analysis or the examination of the extent of recall bias due to a lack of statistical power. Selection bias, whereby the most cognitively impaired were more often unable to recall their birth weight, and were therefore omitted from these analyses also cannot be excluded. However, given that women who reported birth weight were younger and more educated, it argues that the results obtained in this study may underestimate the association of birth weight and cognitive function.

Very low birth weight babies who survived during the years in which the women of this cohort were born were probably healthier than those who did not survive, and only $55 \%$ of the lowest tertile birth weight babies weighed $\leq 6$ pounds. However, survival bias due to the selective survival of healthier low birth weight individuals also likely underestimates the association of birth weight and cognitive function. Much lower birth weight babies survive today than survived 50 or more years ago when the participants in this study were born (Goldenberg and Culhane 2007). Therefore, the association of low birth weight with low cognitive function may be magnified in the future.

The strengths of this study include the comprehensive assessment of cognitive performance and its inclusion of women at older ages. Although the sample was relatively well educated, predominately white and middle-class, which may limit generalizability, potential confounding due to socioeconomic status and early childhood malnutrition is minimized.

In conclusion, of 12 cognitive function measures administered to a sample of older women, small but statistically significant differences by birth weight were observed only on a test of calculation. Although an effect of chance cannot be excluded, these results suggest that difficulties in math found among children of low birth weight may persist throughout life into old age. Additional studies in populations whose birth weight records are retained for life would be useful to further explore this association.

Acknowledgement This work was supported by the National Institutes of Health, National Institutes on Aging, grant numbers AG07181, AG02850.

Open Access This article is distributed under the terms of the Creative Commons Attribution Noncommercial License which permits any noncommercial use, distribution, and reproduction in any medium, provided the original author(s) and source are credited.

\section{References}

Barker DJP (1995) Fetal origins of coronary heart disease. BMJ 311:171-174

Barker DJ (2004) The developmental origins of adult disease. J Am Coll Nutr 23:588S-595S

Blessed G, Tomlinson BE, Roth M (1968) The association between quantitative measures of dementia and of senile change in the cerebral grey matter of elderly subjects. Br J Psychiatry 114:797-811

Borkowski J, Benton AL, Spreen O (1967) Word fluency and brain damage. Neuropsychologia 5:135-140

Botting N, Powls A, Cooke RW, Marlow N (1998) Cognitive and educational outcome of very-low-birthweight children in early adolescence. Dev Med Child Neurol 40:652-660

Buschke H, Fuld PA (1974) Evaluating storage, retention, and retrieval in disordered memory and learning. Neurology 24:1019-1025

Folstein MF, Folstein SE, McHugh PR (1975) “Mini-mental state”. A practical method for grading the cognitive state of patients for the clinician. J Psychiatr Res 12:189-198

Goldenberg RL, Culhane JF (2007) Low birth weight in the United States. Am J Clin Nutr 85:584S-590S

Hack M (2006) Young adult outcomes of very-low-birth-weight children. Semin Fetal Neonatal Med 11:127-137

Hack M, Breslau N, Aram D, Weissman B, Klein N, Borawski-Clark E (1992) The effect of very low birth weight and social risk on neurocognitive abilities at school age. J Dev Behav Pediatr 13:412420

Hales CN, Barker DJP, Clark PMS et al (1991) Fetal and infant growth and impaired glucose tolerance at age 64 years. BMJ 303:10191022

Hamilton BE, Martin JA, Ventura SJ (2006) Births: Preliminary data for 2005. National Vital Statistics Reports, Hyattsville, MD: National Center for Health Statistics 55(11)

Jefferis BJ, Power C, Hertzman C (2002) Birth weight, childhood socioeconomic environment, and cognitive development in the 1958 British birth cohort study. BMJ 325:305

Klebanov PK, Brooks-Gunn J, McCormick MC (1994) School achievement and failure in very low birth weight children. J Dev Behav Pediatr 15:248-256

Klein NK, Hack M, Breslau N (1989) Children who were very low birth weight: development and academic achievement at nine years of age. J Dev Behav Pediatr 10:32-37 
Law CM, de Swiet M, Osmond C et al (1993) Initiation of hypertension in utero and its amplification throughout life. BMJ 306:24-27

Leon DA, Koupilova I, Lithell HO et al (1996) Failure to realise growth potential in utero and adult obesity in relation to blood pressure in 50-year old Swedish men. BMJ 312:401-406

Lithell HO, McKeigue PM, Berglund L et al (1996) The relation of size at birth to non-insulin concentrations in men aged 50 60 years. BMJ 312:406-410

Lorenz JM, Wooliever DE, Jetton JR, Paneth N (1998) A quantitative review of mortality and developmental disability in extremely premature newborns. Arch Pediatr Adolesc Med 152:425-435

Martin JA, Hamilton BE, Sutton PD, Ventura SJ, Menacker FJ, Kirmeyer S (2006) Births: final data for 2004. National Vital Statistics Reports, Hyattsville, MD: National Center for Health Statistics 55(1)

Martyn CN, Gale CR, Sayer AA, Fall C (1996) Growth in utero and cognitive function in adult life: follow up study of people born between 1920 and 1943. BMJ 312:1393-1396

Matte TD, Bresnahan M, Begg MD, Susser E (2001) Influence of variation in birth weight within normal range and within sibships on IQ at age 7 years: cohort study. Bmj 323:310-314

McCance RA, Widdowson EM (1974) Determinants of growth and form. Proc R Soc Lond 185:1-17

Morgane PJ, Austin-LaFrance R, Bronzino J et al (1993) Prenatal malnutrition and development of the brain. Neurosci Biobehav Rev 17:91-128

Reitan R (1958) Validity of the trail-making test as an indicator of organic brain disease. Percept Mot Skills 8:271-276

Richards M, Hardy R, Kuh D, Wadsworth ME (2001) Birth weight and cognitive function in the British 1946 birth cohort: longitudinal population based study. BMJ 322:199203

Richards M, Hardy R, Kuh D, Wadsworth ME (2002) Birthweight, postnatal growth and cognitive function in a national UK birth cohort. Int J Epidemiol 31:342-348

Rickards AL, Ryan MM, Kitchen WH (1988) Longitudinal study of very low birthweight infants: intelligence and aspects of school progress at 14 years of age. Aust Paediatr J 24:19-23

Russell E (1975) A multiple scoring method for the assessment of complex memory functions. J Consult Clin Psychol 43:800 809
Saigal S, Hoult LA, Streiner DL, Stoskopf BL, Rosenbaum PL (2000) School difficulties at adolescence in a regional cohort of children who were extremely low birth weight. Pediatrics 105:325-331

Saigal S, Rosenbaum P, Szatmari P, Campbell D (1991a) Learning disabilities and school problems in a regional cohort of extremely low birth weight (less than $1000 \mathrm{G}$ ) children: a comparison with term controls. J Dev Behav Pediatr 12:294-300

Saigal S, Szatmari P, Rosenbaum P, Campbell D, King S (1991b) Cognitive abilities and school performance of extremely low birth weight children and matched term control children at age 8 years: a regional study. J Pediatr 118:751-760

Shenkin SD, Starr JM, Pattie A, Rush MA, Whalley LJ, Deary IJ (2001) Birth weight and cognitive function at age 11 years: the Scottish Mental Survey 1932. Arch Dis Child 85:189-196

Sorensen HT, Sabroe S, Olsen J, Rothman KJ, Gillman MW, Fischer P (1997) Birth weight and cognitive function in young adult life: historical cohort study. Bmj 315:401-403

Szatmari P, Jones MB, Tuff L, Bartolucci G, Fisman S, Mahoney W (1993) Lack of cognitive impairment in first-degree relatives of children with pervasive developmental disorders. J Am Acad Child Adolesc Psychiatry 32:1264-1273

Taylor HG, Hack M, Klein N, Schatschneider C (1995) Achievement in children with birth weights less than 750 grams with normal cognitive abilities: evidence for specific learning disabilities. J Pediatr Psychol 20:703-719

Taylor HG, Klein N, Drotar D, Schluchter M, Hack M (2006) Consequences and risks of $<1000 \mathrm{-g}$ birth weight for neuropsychological skills, achievement, and adaptive functioning. J Dev Behav Pediatr 27:459-469

Tombaugh TN, McIntyre NJ (1992) The mini-mental state examination: a comprehensive review. J Am Geriatr Soc 40:922-935

Wiener G, Rider RV, Oppel WC, Harper PA (1968) Correlates of low birth weight. Psychological status at eight to ten years of age. Pediatr Res 2:110-118

Weschler D (1945) A standardized memory scale for clinical use. J Psychol 19:87-95

Winick M, Noble A (1966) Cellular response in rats during malnutrition at various ages. J Nutr 89:300-306

Yarbrough DE, Barrett-Connor E, Kritz-Silverstein D, Wingard DL (1998) Birth weight, adult weight, and girth as predictors of the metabolic syndrome in postmenopausal women: the Rancho Bernardo Study. Diabetes Care 21:1652-1658 